\title{
New Features of Chinese University Students' Voluntary Service
}

\author{
$\mathrm{Xu}$ Yifei \\ School League Committee, Nanjing Normal University, Nanjing, 210046, China \\ Email: 21160494@qq.com
}

\begin{abstract}
With the promotion of economic globalization, cultural diversity, market economy and social transformation, the subject, object, form and organization of voluntary services also change gradually. By measures like conducting matrix management, building two-way information platform and offering professional courses, a long-term voluntary service mechanism is established, which can be used as reference in dealing with the new problems brought by such revolution.
\end{abstract}

Keywords: Voluntary service; practice

\section{Introduction}

Since 1993 after the implementation of Chinese young volunteer service, young volunteer has always played a significant role in the service of important activities, environmental protection service, poverty reduction service and community service. University students, as a special group who have received higher education and acquired specialized knowledge and skills, gradually become the main force of young volunteers. With the development of the modern era, university student volunteers themselves, service objects and service content evolve quickly; people's understanding of voluntary service also changes dramatically. Based on the analysis of the data obtained from a survey on the voluntary activities conducted by young volunteers at Nanjing Normal University in recent 3 years, this paper presents some new features of university students' voluntary service nowadays and also proposes some strategies to solve existing problems.

\section{New Features of Voluntary Services Provided by University Students}

With the progress of the Chinese market economy and social transformation, the subject, object, form and organization of voluntary services also change gradually. On one hand, this brings valuable opportunities for university students' voluntary service; on the other hand, this also makes it face new challenges.

\subsection{Changes of University Student Volunteers Organization}

University student volunteers organization is a student union subordinated to school's CCYL committee. Except school's Chinese Young Volunteers Association, university student volunteers organization also has several college branches. However, in practice work, there is a lack of united guidance and management; branches are independent from each other. Nevertheless, this organizational structure is changing gradually. To ensure the smooth progress of a project, volunteers adopt "matrix-type" team pattern at work. To ensure high efficiency of project implementation, team members come from different departments and create and design unique training methods. Thus, all members can give full play to their own strengths; the organization can provide space for them to realize their comprehensive development; whereas, this weakens the status of the original departments to some degree.

The main body of the university student volunteers has shifted from "the generation born in the 1990s" to "the generation born in the 2000s". Their different growing environments lead to their different understandings of voluntary service. This raises new requirements and challenges for the activities held by university student volunteers organization, which is mainly reflected in two aspects: (1) As the generation which lays emphasis on personal development and feeling, these students prefer a freer environment. They can become volunteers after completing a simple registration online. However, this results in loose volunteer management. The majority of volunteers in organization are lacking in effective management. For example, at Nanjing Normal University, once $98 \%$ voluntary activities were accepted by students; but 
only less than $23 \%$ students joined the organization. Moreover, only $75 \%$ students who joined the organization said that they had received training about voluntary work. (2) Most students who participated in voluntary service are freshmen and sophomores. They occupied $87 \%$ of the overall number of volunteer. Furthermore, students who just participated in voluntary service for once occupied $43 \%$ of the total number of volunteer, which indicates that they cannot provide voluntary service for a long period of time.

\subsection{Changes in the Form of University Students' Voluntary Service}

Internet hastens new lifestyles; various "Internet+" innovations emerge one after another. In university, as one of the important hatcheries of creative and innovative projects, "Internet+" thought is quickly accepted by university students. Thus, depending on Internet platform, volunteer service organizations gather more university student volunteers, which enables some voluntary projects to be completed online from planning, launching, organizing to implementing. This provides projects with new energy and vitality. Meanwhile, features of Internet like decentralization, diversity, equality, openness and freedom make it become an "accelerator" of the growth of university students' voluntary service project in the new era. A survey shows that young volunteers associations at all levels in Nanjing Normal University only have about 800 members; however, more than 7000 volunteers have registered online through the Internet platform and participated in voluntary activities.

\section{$3 \quad$ New Problems in University Students' Voluntary Service}

Chinese university students' voluntary service started late. Although it develops rapidly in recent years, there are still numerous problems, which are mainly reflected in the following aspects.

Firstly, unstable volunteer team. A great number of members are enthusiastic in the early days of activities, but with the reduction of curiosity and the lack of matched vocational training and motivation system, most of them decide to drop out after participating activities for a few times. This situation makes university student volunteers organization lack a stable member composition, which has negative influence on the long-term implementation of voluntary activity.

Secondly, non-routine voluntary activity. Although the schedule of activity is designed based on volunteers' course arrangement, there are still conflicts between course teaching and voluntary service. Colleges and universities always attach importance to specialized knowledge offered in courses in student cultivation but neglect the cultivation of their service awareness. Since schools often do not combine course learning with social work together properly, students always give up voluntary service due to time conflicts. This goes against the routinization of voluntary activity.

Thirdly, unprofessional voluntary activity. With the improvement of Chinese people's living standard and the differentiation of their living needs, the service object's needs become much more specific. Single form of activity not only cannot meet the needs of service object, but also makes university student volunteers lose their enthusiasm in service itself, because it is difficult for them to grow up from voluntary activity. Finally, this results in a big drain on volunteer.

Fourthly, asymmetric voluntary information. The traditional mechanism, which asks volunteers to seek information by themselves, is too rigid. There is a lack of a voluntary service supply-demand platform which associates the government, school, hospital, community and volunteer together.

\section{New Measures for University Students' Voluntary Service}

In face of these new features and new problems, improving voluntary service guarantee and incentive mechanism, making voluntary service professional and establishing a two-way information platform by taking advantages of school's organization are the basic approaches to building a modern university students' voluntary service organization.

\subsection{Improve Guarantee and Incentive Mechanism}

Firstly, establish a comprehensive guarantee system so as to provide strong and powerful guarantee for 
voluntary service. Voluntary service asks university students to walk out of campus. Therefore, to guarantee university student volunteers' security in providing voluntary service, it is necessary to keep improving institutional guarantee. Ask teachers to evaluate the content of activity and judge whether short-term insurance is required. Set small team responsibility system. Any voluntary service should be completed by two volunteers or more. All members have to report to their team leader before and after activity; also, after voluntary activity, they have to submit voluntary service registration form for teachers to estimate the security of the following activities in advance.

Secondly, strengthen the construction of attendance, training and incentive system. Establish a more professional volunteer training system for the purpose of meeting the increasingly precise and professional needs of units and individuals seeking for help. Strengthen system assessment, establish a record for university students' voluntary service and assess volunteers' participation. At the end of every semester, individuals and organizations with excellent performance will be given honorary titles and awarded.

Finally, university students' voluntary service organizations are non-profit organizations; their main body is students. Usually, these organizations are financially supported by guidance departments at all levels, which indicates it single financial resource, but results in voluntary service organizations' high dependence on guidance departments and the lack of initiative. In such situation, voluntary service organizations should cooperate with others positively, try to get voluntary service supporting projects from the government and community and get financial support by developing and customizing voluntary projects. In this way, voluntary service organizations can not only make their voluntary services more professional but also build a stable voluntary service team.

\subsection{Promote Voluntary Service to be Curriculum-based}

Firstly, voluntary service should be combined with students' major and develop into special voluntary service projects embodying subjects' and majors' features. For example, Department of philosophy at Nanjing Normal University independently develops "philosophy class" caring program which faces student group in the 9-14 age bracket. The purpose of this program is to stimulate students' initiative, cultivate their diversified thought, enlighten their thought, encourage them to explore the philosophy in life and help them to grow up by a series of mental games. Xinhua Net and some other media have reported this program. At present, 3 sets of course system, 3 teaching plans and 18 classes have been finished designing. According to long-term practice and statistics, 351 people have been involved in this program; the number of audiences has reached 1205; 32 teachers have participated in; the number of volunteer members has reached 168.

Secondly, voluntary service aims to cultivate students "dedication, care, mutual assistance and progress" voluntary spirit and enhance their comprehensive abilities in public affairs. After field visit, the author considers that Taiwan Normal University's practice can be used for reference: it stipulates voluntary service as a required course in the premise of having no influence on the original cultivation plan; it also designs a voluntary service curriculum system covering theory teaching, practice platform and evaluation system. Thus, more university students have chances to participate in voluntary service program. Voluntary service course should follow the principles of cooperation and reciprocity, emphasize on practice and design diverse course content. What's more, voluntary service course should also help university students to understand the academic concept of voluntary service, encourage them to do voluntary service, share, reflect on and give feedback after service. Finally, this course can enhance university students' voluntary service awareness, promote the development of volunteer organizations at university, prosper voluntary service business at university and guide students to focus more on serving society.

\subsection{Construct a Two-way Information Platform}

Construct a voluntary service information system so as to integrate school's and surrounding area's information resources and provide a precondition for two-way communication. Surrounding departments like governments, communities and sub-districts can release task information on the platform; after registering and getting authentication, volunteers can directly check and accept tasks. Afterwards, improve the planning and layout of voluntary service information system. Reinforce information resource planning and protection; make clear of the admittance criteria of organizations and voluntary tasks; collect information about site, event and people concerned; realize resource sharing in the premise of security. For 
example, after volunteers input their specialties, the system can match relevant tasks automatically; and then volunteers can choose the voluntary service programs which are more suitable to them. After service, the department in charge and the organization or individual participating in the service conduct a two-way evaluation. Finally, strengthen the management and maintenance of the operation in voluntary service information system so as to ensure the security and reliability of information.

University students are the constructors of a country's future. They should have not only strong specialized practical abilities but also the enthusiasm for serving society. Only after recognizing the new features of university students' voluntary service, can we better guide and promote university students' voluntary service business.

\section{References}

1. Xi Jinping. Secure a decisive victory in building a moderately prosperous society in all respects and strive for the great success of socialism with Chinese characteristics for a new era [M].Beijing: people's publishing house, 2017

2. Gao Yan. Song of volunteers - chapter 8, unity of knowledge and practice, value exploration and inheritance of Olympic volunteer service [M]. Beijing Jiaotong University 2009-04-01

3. Tan Jianguang. Ten trends in the development of volunteer service in China [J].Youth exploration.2016 (02)

4. Zhang Xiaohong. Exploration of the curriculum path of university volunteer service education [J]. Education study of thoughts. 2011(05). 